\title{
STUDY OF CD4 COUNT IN HIV PATIENTS ON HAART THERAPY
}

\author{
Sreenivasulu Vemula1, Venkateswara Rao K. S. S
}

${ }^{1}$ Associate Professor, Department of Medicine, Anantapur Medical College, Anantapuram, Andhra Pradesh. 2 Professor and HOD, Department of Medicine, Anantapur Medical College, Anantapuram, Andhra Pradesh.

\section{ABSTRACT}

\section{BACKGROUND}

HIV infection has evolved into greatest pandemic in human history with more than 60 million humans currently affected by HIV virus. CD4 cell dysfunction is the hallmark of HIV disease. CD4 count is important for initiation and monitoring of ART and opportunistic infection prophylaxis, we have conducted a study on 100 HIV patients on HAART therapy whose CD 4 count is $<350 /$ MI, follows for 6 months.

\section{MATERIALS AND METHODS}

Inclusion Criteria - (1) HIV confirmed cases with CD 4 count $<350 / \mathrm{mL}>18$ yrs. of age, patients irrespective of CD4 count in clinical stage III and IV. CD4 count assay is done with whole blood stained and analysed by FACS count cytometry using LASER.

\section{RESULTS}

Improvements of CD4 count by a mean of 180.28 cells $/ \mathrm{mm} 3$ was observed. Improvement of CD4 count is slightly more in females. CD4 count was not significant in patients aged $>60 \mathrm{yrs}$. in those with CD4 count of $<350 \mathrm{cells} / \mathrm{mm} 3$, most mode of transmission is heterosexual (94\%). HIV incidents are observed more commonly in non-agricultural labourers (41\%), 46\% has co-existence illness of these tuberculosin was common (pulmonary and extrapulmonary).

\section{CONCLUSION}

1. CD4 count is mandatory in all patients who are confirmed as HIV/AIDS, irrespective of clinical stage since the clinical stage and CD4 count could not correlate. 2. HAART therapy decreases the incidence of opportunistic infections. 3. HAART therapy has improved BMI.

\section{KEYWORDS}

HIV Disease, CD4 Count, HAART Therapy.

HOW TO CITE THIS ARTICLE: Vemula S, Rao VKSS. Study of CD4 count in HIV patients on HAART therapy. J. Evolution Med. Dent. Sci. 2016;5(95):7034-7041, DOI: 10.14260/jemds/2016/1591

\section{BACKGROUND}

Human Immunodeficiency Virus (HIV), the cause of AIDS was first described in 1981. The HIV virus itself was discovered after 2 years, during which time various causes were considered including lifestyle factors and chronic drug abuse. The HIV epidemic spread rapidly and silently before the testing and effective management became available during the early part. HIV type 1 is the aetiologic agent of most cases of AIDS.12 HIV infection has evolved to become greatest pandemic in human history with more than 60 million humans currently infected by the virus. ${ }^{3}$ HIV disease has claimed more than 25 million lives worldwide. ${ }^{4}$ The recent estimate done by National AIDS Control Organisation reports 2.4 million HIV infected people in India. India has the second highest HIV burden in the world next to South Africa. ${ }^{5}$ It is an acquired disease for which no permanent cure has been found till date, and consequently has a great impact on the quality of life of a patient. HIV/AIDS infection results in diverse clinical

Financial or Other, Competing Interest: None.

Submission 07-11-2016, Peer Review 20-11-2016,

Acceptance 21-11-2016, Published 28-11-2016.

Corresponding Author:

Dr. Sreenivasulu Vemula,

D. No. 6-4-53-1, Maruti Nagar,

Anantapur, Andhra Pradesh.

E-mail: sreenivasuluvemula9@gmail.com,

venkateswararao7@yahoo.co.in

DOI: 10.14260/jemds/2016/1591

\section{(c) (i) $\odot$}

manifestations from asymptomatic carriage to life-threatening opportunistic diseases due to ongoing viral replication, producing a sequential decline in and ablation of cellmedicated immunity. There is a specific decline in the $\mathrm{CD}_{4}+$ helper $\mathrm{T}$ cells, resulting in inversion of the normal $\mathrm{CD}_{4} / \mathrm{CD}_{8} \mathrm{~T}$ cell ratio and deregulation of B-cell antibody production. ${ }^{6}$ Immune responses to certain antigens begin to decline and the host fails to adequately respond to opportunistic infections and normally harmless commensal organisms. Because the defect preferentially affects cellular immunity, the infections tend to be non-bacterial (Fungal, viral). The acquired immune deficiency syndrome is the advanced stage of this illness, in which the infected host can no longer control opportunistic organisms or malignancies that rarely cause illness in immune competent individuals.

Rates of disease progression in HIV infected individuals are highly variable. ${ }^{7}$ HIV subverts the immune system infecting $\mathrm{CD}_{4}+\mathrm{T}$-cells that normally orchestrate immune responses and by activating the immune system and inducting a cytokine milieu that the virus uses to its own explicative advantage.

The lack of recognisable correlates of protective immunity in HIV infection continues to hamper vaccine development and immunotherapeutic approaches. It remains unclear why HIV infected patients experience inexorable immunodeficiency and disease progression despite the presence of robust cytotoxic $\mathrm{CD}_{8} \mathrm{~T}$-cell response and production of neutralising antibodies and antiviral immune responses. HIV reduces ability of thymus gland to replace lost $\mathrm{CD}_{4}$ cells. 
The progress that has been made to date in understanding the pathogenesis of HIV infection is unparalleled. ${ }^{8} \mathrm{CD}_{4}$ T-cell dysfunction is a major hallmark of HIV disease. $\mathrm{CD}_{4}$ count is important for initiation and monitoring of ART and opportunistic infections prophylaxis. Government of India launched ART programme on 1 ${ }^{\text {st }}$ April 2004. Combination of at least three antiretroviral drugs from different groups (Highly Active Anti-Retroviral Therapy) HAART/c ART (Combined ART) is the current standard of care.

Development of newer generation antiretroviral has extraordinary clinical benefits for patients in terms of efficacy, simpler regimens with few toxicities. Since drug therapy is life long, improving patient's commitment and adherence by counselling, regular monitoring is essential for better outcomes.

The prevalence and morbidity due to opportunistic infections can be controlled by improving the general condition and immune status of the individual. ${ }^{9}$ Early HAART initiation is the rule except in Tuberculosis and cryptococcal meningitis, where it is deferred until $4-8$ weeks of specific treatment if $\mathrm{CD}_{4}$ counts are $>50 / \mathrm{mm}^{3}$. In this study, the individual and group wise benefit of antiretroviral therapy on $\mathrm{CD}_{4}+\mathrm{T}$-cell count is evaluated in patients suffering from HIV/AIDS at Government General Hospital, Anantapuramu, Andhra Pradesh.

\section{MATERIALS AND METHODS}

This study is conducted on the patients who attended the ART Centre at Government General Hospital, Anantapuramu between the period from $1^{\text {st }}$ January 2015 to $31^{\text {st }}$ December 2015. A total of 100 patients are included in the study.

\section{Inclusion Criteria}

1. All the patients with confirmed adult HIV/AIDS and with CD4 counts < 350/microlitre (According to WHO guidelines, 2010).

2. Patients irrespective of the $\mathrm{CD}_{4}$ count in clinical stage III and IV.

3. Patients above the age of 18 years.

\section{Exclusion Criteria}

1. All the patients with confirmed adult HIV/AIDS and with $\mathrm{CD}_{4}$ counts $>350 /$ microlitre.

2. Patients who lost for followup.

3. Patients below the age of 18 years.

A chart was prepared with detailed pre- and post-therapy $\mathrm{CD}_{4}$ counts, opportunistic infections at the time of presentation, type of HAART therapy and the pre- and posttherapy body weight.

\section{Confirmation of HIV/AIDS}

All patients who attended the ART Centre at Government General Hospital, Anantapuramu between January 2015 and December 2015 were screened for HIV, and the HIV positive status was confirmed according to NACO guidelines. The blood sample collected at one time was tested with the first kit (Coomb-AIDS). If it was reactive, it was then retested sequentially with the second (ASPEN) and third kits. (Single HIV).

\section{$\mathrm{CD}_{4}$ Count Assay}

Blood was collected in heparinised bottles for flow cytometry analysis. The heparinised blood of about $100 \mu \mathrm{L}$ of whole blood is stained and analysed for $\mathrm{CD}_{4}$ by FACS count cytometry using Laser. $\mathrm{CD}_{4}$ count was repeated after 6 months. ${ }^{10}$

\section{Investigations Considered}

1. Measurement of Weight/BMI.

2. HB\%, TC, DC, ESR.

3. Blood Urea.

4. Serum Creatinine.

5. Urine Analysis.

6. Chest x-ray.

7. Other relevant investigation wherever necessary.

8. Liver Function Tests.

After obtaining the consent from the patient, he/she was included in the study.

\section{RESULTS}

Total number of 100 patients were analysed. Both the initial $\mathrm{CD}_{4}$ count and $\mathrm{CD}_{4}$ count after 6 months of highly active antiretroviral therapy were obtained as follows.

\begin{tabular}{|c|c|c|c|c|c|c|}
\hline \multirow{2}{*}{$\begin{array}{c}\text { Age } \\
\text { Group }\end{array}$} & $\begin{array}{c}\text { Mo. } \\
\text { of } \\
\text { Patients }\end{array}$ & $\%$ & $\begin{array}{c}\text { No. } \\
\text { of } \\
\text { Patients }\end{array}$ & $\%$ & $\begin{array}{c}\text { No. } \\
\text { of } \\
\text { Patients }\end{array}$ & $\%$ \\
\hline $13-20$ & - & $0 \%$ & 1 & $1 \%$ & 1 & $1 \%$ \\
\hline $21-30$ & 14 & $14 \%$ & 16 & $16 \%$ & 30 & $30 \%$ \\
\hline $31-40$ & 23 & $23 \%$ & 12 & $12 \%$ & 35 & $35 \%$ \\
\hline $41-50$ & 16 & $16 \%$ & 9 & $9 \%$ & 25 & $25 \%$ \\
\hline $51-60$ & 4 & $4 \%$ & 2 & $2 \%$ & 6 & $6 \%$ \\
\hline$>60$ & 2 & $2 \%$ & 1 & $1 \%$ & 3 & $3 \%$ \\
\hline \multicolumn{6}{|c|}{ Age and Sex Distribution } \\
\hline
\end{tabular}

\begin{tabular}{|c|c|c|}
\hline & No. of Patients & Mean Age \\
\hline Male & 59 & 38.4 \\
\hline Female & 41 & 33.3 \\
\hline \multicolumn{2}{|c|}{ Mean Age and Sex Distribution } \\
\hline
\end{tabular}

Among the 100 patients studied, males were more commonly affected (59\%) when compared to females (41\%).

\begin{tabular}{|c|c|c|}
\hline Mode & No. of Cases & Percentage \\
\hline Heterosexual & 94 & $94 \%$ \\
\hline Unsafe Injection & 2 & $2 \%$ \\
\hline Men having Sex with Men & 4 & $4 \%$ \\
\hline \multicolumn{2}{|c|}{ Mode of Spread } \\
\hline
\end{tabular}

Among the 100 patients analysed heterosexual transmission was the most common mode of transmission (94\%) with men having sex with men constituting $4 \%$ and unsafe injection constituting $2 \%$.

\begin{tabular}{|c|c|c|}
\hline Occupation & $\begin{array}{c}\text { Number of } \\
\text { Patients }\end{array}$ & Percentage \\
\hline Agricultural Labour & 16 & $16 \%$ \\
\hline
\end{tabular}




\begin{tabular}{|c|c|c|}
\hline $\begin{array}{c}\text { Non-Agricultural } \\
\text { Labour }\end{array}$ & 41 & $41 \%$ \\
\hline Services/Employees & 11 & $11 \%$ \\
\hline Business & 16 & $16 \%$ \\
\hline Housewife & 5 & $5 \%$ \\
\hline Transport & 11 & $11 \%$ \\
\hline \multicolumn{2}{|c|}{ Occupation Distribution of Patients } \\
\hline
\end{tabular}

Regarding occupation 41\% are Non-Agricultural Labourer, $16 \%$ Agricultural Labourer, $16 \%$ are in Business, $11 \%$ are Employees, $11 \%$ are in Transport field and 5\% are housewives.

\begin{tabular}{|c|c|c|}
\hline Income Category & No. of Patients & Percentage \\
\hline Low & 30 & $30 \%$ \\
\hline Middle & 47 & $47 \%$ \\
\hline High & 23 & $23 \%$ \\
\hline Total & 100 & $100 \%$ \\
\hline \multicolumn{2}{|c|}{ Income Category of Patients } \\
\hline
\end{tabular}

Among the 100 patients studied, $47 \%$ of the patients were earning between Rs. 2,000 to 5,000 per month, so it seems middle income socioeconomic status is playing a role in altering sexual behaviour patterns. But this could also be because of a sampling bias; $30 \%$ were earning less than Rs. 2,000 per month and $23 \%$ earning more than Rs. 5,000 per month.

\begin{tabular}{|c|c|c|}
\hline Literacy Status & No. of Patients & Percentage \\
\hline Illiterate & 30 & $30 \%$ \\
\hline Primary Education & 15 & $15 \%$ \\
\hline Secondary Education & 38 & $38 \%$ \\
\hline Inter & 7 & $7 \%$ \\
\hline Degree & 10 & $10 \%$ \\
\hline \multicolumn{3}{|c|}{ Literacy Distribution of Patients } \\
\hline
\end{tabular}

There were 30 Illiterates (30\%) and 75 Literates in the study group. Among the literates $15 \%$ were educated up to primary school level, $38 \%$ up to high school level, $7 \%$ studied intermediate and $10 \%$ studied up to college level.

\begin{tabular}{|c|c|c|}
\hline Locality & No. of Patients & Percentage \\
\hline Rural & 40 & $40 \%$ \\
\hline Urban & 60 & $60 \%$ \\
\hline \multicolumn{2}{|c|}{ Residence/Locality } \\
\hline
\end{tabular}

Geographically, 60\% were from urban area and 40\% from rural area.

\begin{tabular}{|c|c|c|}
\hline History of Smoking & No. of Cases & Percentage \\
\hline Yes & 22 & $22 \%$ \\
\hline No & 78 & $78 \%$ \\
\hline \multicolumn{2}{|c|}{ Smoking Correlation to Sexual Behaviour } \\
\hline
\end{tabular}

Among the 100 patients studied, 22 cases (22\%) have history of smoking.

\begin{tabular}{|c|c|c|}
\hline History of Alcohol Intake & No. of Cases & Percentage \\
\hline Yes & 25 & $25 \%$ \\
\hline No & 75 & $75 \%$ \\
\hline \multicolumn{2}{|c|}{ Alcoholism Correlation to Sexual Behaviour } \\
\hline
\end{tabular}

Among the 100 patients studied, 25 cases (25\%) have history of Alcohol intake. Overall 15 patients out of 100 patients were both alcoholic and smoker showing risk attitude among HIV patients.

\begin{tabular}{|c|c|c|}
\hline Disease & No. of Cases & Percentage \\
\hline Pulm TB & 11 & $11 \%$ \\
\hline Extra-Pulm TB & 12 & $12 \%$ \\
\hline Diabetes Mellitus & 6 & $6 \%$ \\
\hline Hypertension & 5 & $5 \%$ \\
\hline Anaemia & 9 & $9 \%$ \\
\hline Hepatitis-B & 5 & $5 \%$ \\
\hline CAD & 1 & $1 \%$ \\
\hline \multicolumn{3}{|c|}{ Associated Illness/Disease Configuration } \\
\hline
\end{tabular}

Among the 100 patients studied, 46 patients had coexisting illness. Extrapulmonary tuberculosis was present in 12 patients, pulmonary tuberculosis in 11 patients and Diabetes Mellitus in 6 patients, Hypertension in 5 patients, 9 were anaemic, 2 patients had Hepatitis-B infection, 1 patient had history of CAD. So tuberculosis was the most common opportunistic infection in the study population. The associated illness was diagnosed at the time of the initial diagnosis of HIV and it seems HAART decreases the incidence of significant opportunistic infections.

\begin{tabular}{|c|c|c|c|}
\hline CD4 Count & Male & Female & Total \\
\hline$<50$ & 10 & 5 & 15 \\
\hline $51-100$ & 15 & 4 & 19 \\
\hline $101-150$ & 11 & 5 & 16 \\
\hline $151-200$ & 8 & 5 & 13 \\
\hline $201-250$ & 6 & 7 & 13 \\
\hline $251-300$ & 5 & 7 & 12 \\
\hline $301-350$ & 3 & 7 & 10 \\
\hline$>350$ & 1 & 1 & 2 \\
\hline \multicolumn{4}{|c|}{ CD $_{4}$ Cell Count Comparison } \\
\hline
\end{tabular}

\begin{tabular}{|c|c|}
\hline CD $_{4}$ Cell Count & Mean \pm SD \\
\hline Pre-ART & $164.96 \pm 107.33$ \\
\hline Post-ART 6 months followup & $345.24 \pm 184.69$ \\
\hline
\end{tabular}

Among the 100 patients analysed for the impact of HAART on $\mathrm{CD}_{4}$, the mean $\mathrm{CD}_{4}$ count at the time of presentation is 164.96 and increase of 180.28 cells $/ \mathrm{mm} 3$ was noted after 6 months of HAART at 345.24 , which was statistically significant when analysed by paired ' $t$ ' test which showed the ' $P$ ' value of $<0.001$.

\begin{tabular}{|c|c|}
\hline CD $_{4}$ Cell Count & Male \\
\hline Pre-ART & $139.97 \pm 93.29$ \\
\hline Post-ART 6 months followup & $309.78 \pm 179.44$ \\
\hline \multicolumn{2}{|c|}{ Comparative Analysis of Initial and } \\
Followup CD Count in Males $^{2}$
\end{tabular}

In the male subgroup, mean $\mathrm{CD}_{4}$ count at the time of presentation was 139.96 and after 6 months ART followup was 309.78 with rise of 169.81 cells $/ \mathrm{mm}^{3}$.

\begin{tabular}{|c|c|}
\hline CD $_{\mathbf{4}}$ Cell Count & Female \\
\hline Pre-ART & $200.93 \pm 116.82$ \\
\hline Post-ART 6 months followup & $396.27 \pm 182.24$ \\
\hline \multicolumn{2}{|c|}{ Comparative Analysis of Initial and } \\
Followup CD Count in Females $^{2}$
\end{tabular}


In the female subgroup, mean $\mathrm{CD}_{4}$ count at the time of presentation was 200.93 and after 6 months ART followup was 396.27 with rise of 195.34 cells $/ \mathrm{mm}^{3}$.

\begin{tabular}{|c|c|c|c|}
\hline $\begin{array}{c}\text { Initial CD } \\
\text { Count } \\
\text { Group }\end{array}$ & $\begin{array}{c}\text { No. of } \\
\text { Patients }\end{array}$ & $\begin{array}{c}\text { Pre-ART } \\
\text { CD }_{\mathbf{4}} \text { Count }\end{array}$ & $\begin{array}{c}\text { Post-ART } \\
\text { CD }_{\mathbf{4}} \text { Count }\end{array}$ \\
\hline$<50$ & 15 & $24.2 \pm 16.12$ & $160.07 \pm 81.51$ \\
\hline $51-100$ & 19 & $75.79 \pm 15.25$ & $222.89 \pm 92.40$ \\
\hline $101-150$ & 16 & $121.31 \pm 16.80$ & $308.31 \pm 97.61$ \\
\hline $151-200$ & 13 & $181.15 \pm 12.55$ & $420.08 \pm 161.57$ \\
\hline $201-250$ & 13 & $222.69 \pm 13.76$ & $396.46 \pm 192.09$ \\
\hline $251-300$ & 12 & $282.17 \pm 13.87$ & $491.17 \pm 185.54$ \\
\hline $301-350$ & 10 & $321 \pm 16.53$ & $537.6 \pm 145.68$ \\
\hline$>350$ & 2 & $453 \pm 141.42$ & $535 \pm 190.92$ \\
\hline Group Wise Analysis of Initial and Followup CD Count \\
\hline \multicolumn{4}{|c}{}
\end{tabular}

\begin{tabular}{|c|c|c|c|}
\hline $\begin{array}{c}\text { Age } \\
\text { Group }\end{array}$ & $\begin{array}{c}\text { No. of } \\
\text { Patients }\end{array}$ & $\begin{array}{c}\text { Pre-ART } \\
\text { CD } 4 \text { Count }\end{array}$ & $\begin{array}{c}\text { Post-ART } \\
\text { CD } \text { Count }\end{array}$ \\
\hline $13-20$ & 1 & 334 & 502 \\
\hline $21-30$ & 30 & $195.5 \pm 114.26$ & $388.37 \pm 195.32$ \\
\hline $31-40$ & 35 & $157.74 \pm 106.04$ & $325.66 \pm 195.65$ \\
\hline $41-50$ & 25 & $125.48 \pm 85.79$ & $312.96 \pm 162.30$ \\
\hline $51-60$ & 6 & $114 \pm 75.94$ & $298 \pm 167.38$ \\
\hline$>60$ & 3 & $288.33 \pm 69.83$ & $452 \pm 122$ \\
\hline \multicolumn{4}{|c|}{ Age Wise Analysis of Initial and Followup CD Count } \\
\hline
\end{tabular}

\section{DISCUSSION}

\section{Prior to Treatment}

Fall in $\mathrm{CD}_{4}$ count that happens in asymptomatic phase of HIV infection follow three types of patterns. These are the rapid, typical and slow patterns. In rapid decliners with $\mathrm{CD}_{4}$ cell crash, the counts fall by approximately 50 per month from a normal value of $800-1200$ cells $/ \mathrm{mm}^{3}$. In typical situation, the fall is around 50 - 100 cells per year. In slow progressors, the counts continue at higher level for years without significant fall. This is usually not in relation with rise in viral load that happens over a period of time.

\section{On Treatment}

The elevation in $\mathrm{CD}_{4}$ cell count is commonly used to assess the response to ART. But anti-retroviral drugs per se have no effect on $\mathrm{CD}_{4}$ cells. They modify or inhibit various stages of viral replication, then viral levels in the body are reduced, $\mathrm{CD}_{4}$ cell depletion gets arrested leading to rise in $\mathrm{CD}_{4}$ cell count. Thus, fall in HIV viral loads and rise in $\mathrm{CD}_{4}$ cell count should occur in a predictable inverse relationship.

To improve treatment outcome, ART adherence counselling should target specific personal barriers to ART adherence like lack of family support, health and sexual life concerns, desire to have children and family instability.

Factors such as the impact of hepatitis, TB co-infection or pregnancy and anaemia on antiretroviral therapy choice, toxicity and regimen change should also be examined before initiation of antiretroviral therapy.

Reconstitution of $\mathrm{CD}_{4}$ T-cells during viral suppression generally follows a biphasic pattern, typically showing burst of increase of $50-120$ cells $/ \mathrm{mm}^{3}$ during first three months followed by a second slower phase of T-cell repopulation with average rate of increase of 2 to 7 cells $/ \mathrm{mm}^{3}$ per month.

The Aim of Current study is to primarily evaluate the impact of ART on change in $\mathrm{CD}_{4}$ count. (A total of 1144 (Male $561+$ Female 583) patients were confirmed HIV positive between $1^{\text {st }}$ January 2015 to $31^{\text {st }}$ December 2015 in ART centre at Government General Hospital, Anantapuramu. Antiretroviral Therapy was initiated in 903 (Male $438+$ Female 465) patients with WHO/NACO eligible $\mathrm{CD}_{4}$ count/stage including previously diagnosed patients). Among 1144 patients confirmed HIV positive from January 2015 to December 2015,100 patients having $\mathrm{CD}_{4}$ counts $<350$ or WHO Stage III and IV irrespective of $\mathrm{CD}_{4}$ count were included in the study and after six months followup repeat $\mathrm{CD}_{4}$ count was done.

These patients' $\mathrm{CD}_{4}$ counts pre- and post-anti-retroviral therapy are analysed and represented in the study; 398 patients were lost to follow-up for various reasons (Male 223 + Female 175).

Prevalence of HIV infection is more in low and middle income groups with $30 \%$ and $47 \%$ respectively in current study, most of them being agricultural and non-agricultural labourers. Predominant mode of transmission is heterosexual (94\%) in current study. Social stigma may be the cause for under disclosure/reporting of MSM and female sex worker status.

There were sex related changes in composition of the subjects with respect to age. Male, female ratio being 3:2. Most common age group affected in males was 31 - 40 years and among females it was 21 - 30 years' age group. Young adults account for much of HIV burden. The change in $\mathrm{CD}_{4}$ count in most of the subjects has been noticed. Male and female subjects showed statistically significant improvement by 169.81 and 195.34 cells $/ \mathrm{mm}^{3}$ after 6 months ART with females having slightly better increments in $\mathrm{CD}_{4}$ counts.

In this study, it was found that the mean age of seeking medical advice is 33.3 years in females and 38.4 years in males. There is male preponderance probably due to risk behaviour. In current study $>60$ years' age group showed less significant improvement in $\mathrm{CD}_{4}$ count post 6 months ART. Downregulation of the immune system with advancing age could be the reason for less significant growth in $\mathrm{CD}_{4}$ count in above 60 years' age group. The subjects above 50 years' age group are low in number when compared to younger age groups.

Some of the previous studies evaluated the increase in $\mathrm{CD}_{4}$ count with relation to sex and also to viral load. With the available resources the study involves evaluation of age, gender and initial $\mathrm{CD}_{4}$ count group wise impact of ART on change in $\mathrm{CD}_{4}$ count. Most of the patients seeking medical therapy occurred in a range of low $\mathrm{CD}_{4}$ count between 0 - 100 (34\% in current study). The clinical and epidemiological importance of this finding is that lower the $\mathrm{CD}_{4}$ count more likely are the patients to develop opportunistic infections like Pneumocystis Carinii pneumonia. $\mathrm{CD}_{4}$ count is important in approaching management of HIV infection like opportunistic infections prophylaxis.

From the statistics, it understood that the mean $\mathrm{CD}_{4}$ count at the time of presentation was 139.97 in males and 200.93 in females. This when compared to the normal $\mathrm{CD}_{4}$ count is much less. The mean increase of the count when the total subjects are taken is also significant $(\mathrm{P}<0.001)$. The mean count after therapy was 309.78 in males and 396.27 in females.

The seropositivity was found to be associated with a low level of literacy. Truck drivers and labourers who migrated for their livelihood were the important occupational groups among the males, who needed awareness in the current preventive programme for AIDS. 
Even in the very low initial count, females when compared to males the response to HAART is good for females than in males with less incidence of poor responders. The males also show a rise in count, which is significant. Castagno et al in their study showed that stopping HAART resulted in gradual decline in the number of $\mathrm{CD}_{4}$ cells. Current study does not include the effect of individual antiretroviral drugs. The drugs are used in combination of individual agents. While analysing the data, it became evident that the number of subjects in the study showed good response to therapy.

These findings show the definitive impact of HAART in increasing $\mathrm{CD}_{4}$ cells in AIDS patients. The number of new HIV infection is on decline and the life expectancy of the HIV infected person is almost reaching to that of a normal individual. Success achieved by ART has now transformed the HIV infection from being a virtual death sentence to a chronic manageable illness. ${ }^{11,12}$

BMI was missing in patients too weak to stand in our cohort, and thus with poor prognosis. Studies in Africa have assessed the short-term prognostic value of nutritional indicators at HIV diagnosis on survival. ${ }^{13}$ These studies showed a correlation between a low BMI at enrolment in HIV care and subsequent treatment outcome.

Life expectancies of patients with baseline $\mathrm{CD}_{4}$ counts > 200 cells/ $\mu \mathrm{L}$ were between $70 \%$ and $86 \%$ of those in HIVnegative adults of the same age and sex, and life expectancies were increased by $15 \%-20 \%$ in patients who had survived 2 years after starting ART. 14

Unrecognised TB at the time of ART initiation resulted in impaired $\mathrm{CD}_{4}$ recovery compared with $\mathrm{TB}$ treated before ART initiation. More vigilant screening with more sensitive and rapid TB diagnostics prior to ART initiation is needed to decrease the risk of ART-associated TB and sub-optimal immune reconstitution. In current study subjects presenting with a very low count initially, often with high WHO stage due to TB co-infection after HAART were among poor responders in the $\mathrm{CD}_{4}$ count improvement. Patients with no or a small increase in $\mathrm{CD}_{4}$ counts after 6 months of HAART and low $\mathrm{CD}_{4}$ levels at initiation of therapy have an increased risk of HIVrelated disease. In dually infected patients, it suggests that TB additionally influences the reduction of $\mathrm{CD}_{4}$ counts in HIV patients. 15

Routine HIV viral load monitoring is not generally available in national ART programme and treatment failure is frequently suspected by immunological and/or clinical failure. All suspected treatment failure cases are confirmed by viral load assay to determine eligibility of second line ART. Typically, biological failure precedes immunological failure and lastly clinical failure.

Le $\mathrm{T}$ et al study "Enhanced $\mathrm{CD}_{4}+\mathrm{T}$-cell recovery with earlier HIV-1 antiretroviral therapy" - A transient, spontaneous restoration of $\mathrm{CD}_{4}+\mathrm{T}$-cell counts occurs in the 4month time window after HIV-1 infection. Initiation of ART during this early period is associated with an enhanced likelihood of recovery of $\mathrm{CD}_{4}+$ counts. HIV-infected patients with higher baseline $\mathrm{CD}_{4}(+) \mathrm{T}$-cell counts could result in higher total $\mathrm{CD}_{4}(+) \mathrm{T}$-cell counts, thereby achieve a better immune recovery. These results support current guidelines to start HAART at a threshold of 350 cells/microl.16,17 Among HIV-infected Nigerian individuals, HBV confection, especially among those with high levels of HBV replication, was associated with lower $\mathrm{CD}_{4}+\mathrm{T}$-cell counts at ART initiation, independent of HIV RNA level. Patients with HBeAg-positive status had a slower biological response to ART compared with HBeAg-negative patients. Further work is needed to understand the effects. Higher DNA and detectable HBeAg levels were independently associated with lower $\mathrm{CD}_{4}+\mathrm{T}$-cell counts at ART initiation, but not with higher HIV loads. 18

HIV-positive patients who currently smoke have increased mortality and decreased quality of life as well as increased respiratory symptoms, COPD and bacterial pneumonia. These findings suggest that smoking cessation should be emphasised for HIV-infected patients.

Antiretroviral Therapy (ART) adherence is a key to successful treatment of HIV infection and alcohol is a known barrier to adherence. Beyond intoxication, ART adherence is impacted by beliefs that mixing alcohol and medications is toxic participants who endorsed interactive toxicity beliefs were significantly more likely to miss medications on drinking days. Demonstrated significantly poorer ART adherence were less likely to be viral suppressed and more likely to have $\mathrm{CD}_{4}$ counts under $200 / \mathrm{mm}^{3}$. Among HIV-infected Indians in primary care, predictors of unprotected sex included alcohol use and desire for children. Prevention interventions for Indian couples should integrate reproductive health and alcohol use counselling at entry into care. ${ }^{19}$

Studies have yielded conflicting results regarding alcohol's influence on HIV outcomes, particularly after Highly Active Antiretroviral Treatment (HAART). Discrepant findings may be related to confounding variables including gender, patterns of alcohol abuse and type of alcohol beverage beyond the amount consumed. Liquor was associated with thymus deterioration and thus with poorer viro-immune outcomes after HAART.20 Sub-typing participants by alcohol consumption patterns seems to be clinically relevant and needs to be accounted for in future studies. ${ }^{21}$

Antiretroviral Therapy (ART) for treating HIV infection is now being turned towards HIV prevention. The Swiss Federal Commission for HIV/AIDS has declared that HIV-positive persons who are treated with ART have an undetectable viral load, and are free of co-occurring Sexually Transmitted Infections (STIs) should be considered non-infectious for sexual transmission of HIV. This study examined the implications of these assumptions in a sample of HIV-positive individuals who drink alcohol. Adherence was generally suboptimal. Less than half of people who drank alcohol and took ART met the Swiss criteria for no infectiousness. Poor adherence and prevalent STI threaten the long-term potential of using ART for prevention among alcohol drinkers.

Timely initiation of Antiretroviral Therapy (ART) is particularly important for HIV-discordant couples, because viral suppression greatly reduces the risk of transmission to the uninfected partner. ${ }^{22}$ Antiretroviral have substantial promise for HIV-1 prevention, either as Antiretroviral Treatment (ART) for HIV-1 infected persons to reduce infectiousness or as pre-exposure prophylaxis (PrEP) for HIV1 uninfected persons to reduce the possibility of infection with HIV-1, HIV-1 serodiscordant couples in long-term partnerships (one member is infected and the other is uninfected) are a priority for prevention interventions. Earlier ART and PrEP might both reduce HIV-1 transmission in this group, but the merits and synergies of these different approaches have not been analysed. 
Methods and Findings: We constructed a mathematical model to examine the impact and cost-effectiveness of different strategies including earlier initiation of ART and/or PrEP for HIV-1 prevention for serodiscordant couple. Although, the cost or PrEP is high, the cost per infection averted is significantly offset by future savings in lifelong treatment, especially among couples with multiple partners, low condom use and a high risk of transmission. In some situations, highly effective PrEP could be cost-saving overall.

To keep couples alive and without a new infection, providing PrEP to the uninfected partner could be at least as cost-effective as initiating ART earlier in the infected partner if the annual cost of PrEP is $<40 \%$ of the annual cost of ART and PrEP is $>70 \%$ effective. ${ }^{23}$

In current study, the effect of ART on prevention of sexual transmission of HIV in serodiscordant couples was not evaluated. There was a higher incidence of LART in men than in women high alcohol consumption singlehood and level of education lower than secondary were associated to LART at vicariate analysis. Male sex was the only associated factor both in vicariate and multivariate analysis. Our data reinforce the need of expanding HIV testing and should assist programs to define actions promoting early entry in HIV care. ${ }^{24} \mathrm{~A}$ significant proportion of those initiating Antiretroviral Treatment (ART) for HIV infection are lost to follow-up. Causes (Including HIV symptoms, quality of life, depression, herbal treatment and alcohol use) for discontinuing ART follow-up in predominantly rural resource - limited settings are not well understood.

The high early mortality rates indicate that patients are enrolling into ART programmes with far too advanced immunodeficiency; median $\mathrm{CD}_{4}$ cell counts 119 (IQR $=59$ 163). Causes of late access to the ART programme, such as delays in health care access (Delayed health care seeking), health system delays or inappropriate treatment criteria need to be addressed. Differences in health status (Lower $\mathrm{CD}_{4}$ cell counts and higher depression scores) should be taken into account when initiating patients on ART. Treating depression at ART initiation is recommended to improve treatment outcome. 25

Quality of Life (QOL) among patients with HIV/AIDS has been shown to improve once treatment with Antiretroviral Therapy (ART) has been started, older age, rural dwelling, alcohol use, $\mathrm{CD}_{4}$ count less than 200 and ART duration of less than one year were significantly associated with lower PHS scores.

Alcohol consumption has a direct association with depression in HIV infected patients on ART, extreme elevations of ALT were infrequent but minor elevations were common so that patient-linked variables such as use of alcohol intake must be taken into account for better clinical management of ART patients.

This study found a high symptom burden among HIV patients, which significantly decreased with progression on antiretroviral treatment. The utilisation of different symptom management strategies (Medical, spiritual, complementary and traditional) should be taken into consideration in HIV treatment. ${ }^{26}$ In India, clinician should be taken into consideration all possible risk factors associated with the use of HAART in order to avoid and minimise ADRs. As initial $\mathrm{CD}_{4}$ $+\mathrm{T}$-cell count and age of patient decides the rise of $\mathrm{CD}_{4}+\mathrm{T}$-cell counts with HAART. HAART should be initiated at the earliest age in order to attain maximum $\mathrm{CD}_{4}+\mathrm{T}$-cell counts recovery. ${ }^{27}$

Little is known about the impact of combination of HIV prevention interventions for men who have sex with men (MSM) HPTN 052 randomised controlled trial, ART used in combination with condoms and counselling reduced HIV transmission by $96.4 \%$. Evidence is growing that wider, earlier initiation of ART could reduce population-level incidence of HIV. However, the full benefits of this strategy will probably need universal access to a very early ART and excellent adherence to treatment. Challenges to this approach are substantial. First, not all HIV-infected individuals can be located, especially people with acute and early infection who are most contagious. Second, the ability of ART to prevent HIV transmission in men who have sex with men (MSM) and people who use intravenous drugs has not been shown. Indeed, the stable or increased incidence of HIV in MSM in some communities where widespread use of ART has been established emphasises the concern that not enough is known about treatment as prevention for this crucial population. ${ }^{28}$

There is interest in expanding ART to prevent HIV transmission, but in the group with the highest levels of ART use, men-who-have-sex-with-men (MSM), numbers of new infections diagnosed each year have not decreased as ART coverage has increased for reasons which remain unclear. ART has almost certainly exerted a limiting effect on incidence. Increased condom use should be promoted to avoid the erosion of the benefits of ART and to prevent other serious sexually transmitted infections. ${ }^{29}$

Compared with high-income countries, patients starting HAART in low-income settings had lower $\mathrm{CD}_{4}$ cell counts (Median 108 cells per muL vs 234 cells per muL) were more likely to be female ( $51 \%$ vs $25 \%$ ), and more likely to start treatment with a Non-Nucleoside Reverse Transcriptase Inhibitor (NNRTI). It remains unclear whether the natural course of Human Immunodeficiency Virus (HIV) differs in subjects infected through Injecting Drug Use (IDU). People with a history of IDU had a statistically significant faster decline in $\mathrm{CD}_{4}$ cells.

Food incentives, medical incentives, streamlining services to minimise patient visits may decrease attrition, increased pre-ART retention, but the quality of the current evidence base is low. Few studies have investigated combined interventions or assessed the impact of interventions across the HIV cascade.

Anti-Retroviral Therapy (ART) in pregnancy is a crucial intervention in the Prevention of Mother-to-Child Transmission (PMTCT) of HIV. It is recognised that mother-tochild transmission is reduced with each week on ART. ${ }^{30}$ All seropositive mothers should be assessed for ART eligibility, if not they require ARV prophylaxis without any intervention, risk of HIV transmission from pregnant women to her child is around 20 - 45\%. Women conceiving on an effective HAART regimen should continue ART ante-partum, intra-partum and post-partum. The initial comparative immunological advantage possessed by fertile women before they become pregnant is subsequently lost as a result of their pregnancy with a decrease in immunoglobulin, complement and cell mediated immunity level during pregnancy. Women should be informed about the potential negative effect of pregnancy on their immunological status and should be offered contraception. In resource-limited settings, women 
determined to become pregnant should be given priority for ART if eligible.

Rural women living with AIDS (WLA) on antiretroviral therapy self-reported a high prevalence of physical symptoms, high levels of depressive symptoms and major barriers to accessing health care. $\mathrm{CD}_{4}$ levels, body weight and basal metabolic rate were also low. While the rural and urban WLA faced similar health care challenges, the demographic characteristics of the rural women may make them more vulnerable as they are less adherent to ART and slimmer than their urban counterparts.

Little is known about the variability of $\mathrm{CD}_{4}$ counts in the general population. $\mathrm{CD}_{4}$ counts are primarily determined by sex in HIV-uninfected adults and by sex, age and duration of antiretroviral treatment in HIV-infected adults. Lower $\mathrm{CD}_{4}$ counts at ART initiation in men could be a consequence of lower $\mathrm{CD}_{4}$ cells counts before HIV acquisition in multivariable regression analysis, women had 19.4\% (95\% Confidence Interval (CI) 16.1-22.9) higher $\mathrm{CD}_{4}$ counts than men, controlling for age, HIV status, urban/rural residence, household wealth, education, BMI, self-reported tuberculosis, high blood pressure, other chronic illnesses and sample processing delay.

A baseline genotype HIV test for all patients of acute HIV infection may be necessary, though they may not be opting for therapy because anti-retroviral drugs are accessible since more than 25 years and $6-16 \%$ of individuals who are newly infected might have acquired the HIV strains, which are drug resistant.

\section{CONCLUSION}

1. In this study, there were 100 patients with $\mathrm{CD}_{4}$ count of less than 350/uL who were started on highly active antiretroviral therapy and followed up, whose followup $\mathrm{CD}_{4}$ count was done after 6 months of HAART and analysed to evaluate the impact of HAART on $\mathrm{CD}_{4}$ cell count.

2. $\mathrm{CD}_{4}$ cell count is mandatory in all the patients who are confirmed as HIV/AIDS, irrespective of the clinical stage, since the clinical stage and the $\mathrm{CD}_{4}$ count need not correlate.

3. Patients were classified into eight groups as per the initial $\mathrm{CD}_{4}$ cell count.

\begin{tabular}{|c|c|c|}
\hline CD $_{4}$ Count & Male & Female \\
\hline$<50$ & 9 & 5 \\
\hline $51-100$ & 15 & 5 \\
\hline $101-150$ & 10 & 5 \\
\hline $151-200$ & 10 & 4 \\
\hline $201-250$ & 6 & 7 \\
\hline $251-300$ & 5 & 7 \\
\hline $301-350$ & 3 & 7 \\
\hline$>350$ & 1 & 1 \\
\hline
\end{tabular}

4. In these 100 patients, 6 months followup $\mathrm{CD}_{4}$ count was analysed and it showed an improvement by a mean of 180.28 cells $/ \mathrm{mm} 3$, which was also statistically significant when analysed by using the paired ' $\mathrm{t}$ ' test that showed a ' $p$ ' value of $<0.001$.

5. When the groups were analysed individually all the groups age wise 5, initial CD4 count group wise, gender wise showed statistically significant improvement in CD4 counts post 6 -month therapy except in groups $>60$ years and initial CD4 count $>350$ group where improvement was not significant.

6. HAART has improved the BMI/weight reflecting improvement in general condition and well-being of the patients. This could also be attributed to the nutritional advice and intervention.

7. HAART decreases the incidence of opportunistic infections as evidenced by improved clinical stages.

8. Tuberculosis was the most common opportunistic infection.

9. CD4 cell count monitoring is very important and could be done every 3 months, but for resource constraints it is being done every 6 months.

\section{REFERENCES}

1. UNAIDS gap report 2014.

2. HIV Estimations 2012 Report Released by Government of India Ministry of Health and Family Welfare 30-November2012.

3. NACO annual report 2013-14.

4. WHO guidelines for initiation of ART in adults and adolescents 2010

5. Gilks CF, Crowley S, Ekpini R, et al. The public health approach to anti retroviral therapy is defined in the following article. The WHO public-health approach to antiretroviral treatment against HIV in resource limited settings. Lancet 2006;368(9534):505-10.

6. Anthony SF, Lane HC. Harrison's principles of internal medicine. 18th edn. chapter 189. 1516-151.

7. BB Rewari, Sinha S. API text book of medicine 2012: 10235.

8. Sepkowitz KA. AIDS-the first 20 years. N Engl J Med 2001;344(23):1764-72.

9. Kirch W. Encyclopedia of public health. New York: Springer 2008:676-7.

10. DeSimone JA, Pomerantz RJ, Babinchak TJ. Inflammatory reactions in HIV-1 infected persons after initiation of highly active antiretroviral therapy. Ann Intern Med 2000;133(6):447-54.

11. Fauci AS. Multifactorial nature of human immunodeficiency virus diseases: implications for therapy. Science 1993;262(5136):1011-8.

12. Johnson LF, Mossong J, Dorrington RE; et al. Life expectancies of South African adults starting antiretroviral treatment: collaborative analysis of cohort studies. Plos Medicine 2013;10(4):e1001418.

13. Wanchu A, Kuttiatt VS, Sharma A, et al. CD4 cell count recovery in HIV/TB co-infected patients versus TB uninfected HIV patients. Indian Journal of Pathology and Microbiology 2010;53(4):745-9.

14. Le T, Wright EJ, Smith DM, et al. Enhanced CD4+ T-cell recovery with earlier HIV-1 antiretroviral therapy. The New England Journal of Medicine 2013;368(3):218-30.

15. Liu ZY, Guo FP, Han Y, et al. Impact of baseline $\mathrm{CD} 4(+) \mathrm{T}$ cell counts on the efficacy of nevirapine-based highly active antiretroviral therapy in Chinese HIV/AIDS patients: a prospective, multicentric study. Chinese Medical Journal (Engl) 2009;122(20):2497-502. 


\section{Jemds.com}

16. Crothers K, Griffith TA, McGinnis KA, et al. The Impact of cigarette smoking on mortality, quality of life and comorbid illness among HIV-positive veterans. Journal of General Internal Medicine 2005;20(12):1142-5.

17. Kalichman SC, Grebler T, Amaral CM, et al. International non-adherence to medications among HIV positive alcohol drinkers: prospective study of interactive toxicity beliefs. Journal of General Internal Medicine 2013;28(3):399-405.

18. Kahn TR, Desmond M, Rao D, et al. Delayed initiation of antiretroviral therapy among HIV-discordant couples in Kenya. AIDS Care 2013;25(3):265-72.

19. Miguez-Burbano MJ, Maria Jose; Lewis JE, Fishman J, et al. The influence of different types of alcoholic beverages on disrupting highly active antiretroviral treatment (HAART) outcome. Alcohol Alcohol 2009;44(4):366-71.

20. Kalichman SC, Grebler T, Amaral CM, et al. Assumed infectiousness, treatment adherence and sexual behaviours: applying the Swiss Statement on infectiousness to HIV-positive alcohol drinkers. HIV Medicine 2013;14(5):263-72.

21. Warley E, Galimberti GF, Vieni MI, et al. Factors associated to late clinical stage at the initiation of anti retroviral therapy. Medicina (Buenos Aires) 2012;72(5):367-70.

22. Peltzer K, Ramlagan S, Khan MS, et al. The social and clinical characteristics of patients on antiretroviral therapy who are "lost to follow-up" in KwaZulu-Natal, South Africa: a prospective study. SAHARA J 2011;8(4):179-86.

23. Bajunirwe F, Tisch DJ, King $\mathrm{CH}$, et al. Quality of life and social support among patients receiving anti retroviral therapy in Western Uganda. AIDS Care 2009;21(3):271-9.
Original Research Article

24. Peltzer K. HIV-related symptoms and management in HIV and antiretroviral therapy patients in KwaZulu-Natal, South Africa: a longitudinal study. SAHARA J 2013;10(2):96-104.

25. Rajesh R, Vidyasagar S, Varma DM, et al. A prospective study of highly active antiretroviral therapy in Indian Human Immunodeficiency Virus positive patients. The International Journal of Risk \& Safety in Medicine 2013;25(1):53-65.

26. Phillips AN, Cambiano V, Nakagawa F, et al. Increased HIV incidence in men who have sex with men despite high levels of ART-induced viral suppression: analysis of an extensively documented epidemic. PLOS ONE 2013;8(2):e55312.

27. Braitstein P, Brinkhof MW, Dabis F, et al. Mortality of HIV1-infected patients in the first year of antiretroviral therapy: comparison between low-income and highincome countries. Lancet 2006;367(9513):817-24.

28. Meijerink H, Wisaksana R, Iskandar S, et al. Injecting drug use is associated with a more rapid CD4 cell decline among treatment naïve HIV-positive patients in Indonesia. Journal of the International AIDS Society 2014;17(1):18844.

29. Govindasamy D, Meghij J, Negussi EK, et al. Interventions to improve or facilitate linkage to or retention in pre-ART (HIV) care and initiation of ART in low- and middle-income settings - a systematic review. Journal of International AIDS Society 2014;17(1):19032.

30. Nyamathi A, Heravian A, Salem B, et al. Physical and mental health of rural southern Indian women living with AIDS. Journal of International Association of Providers of AIDS Care 2013;12(6)391-6. 